\title{
ENVIRONMENTAL ASSESSMENT ON METHYL ESTER PRODUCTION FROM PALM FEEDSTOCK: A CASE STUDY
}

\author{
NOORAZAH ZOLKARNAIN*; ZULINA ABD MAURAD*; RAZMAH GHAZALI* and ZAINAB IDRIS*
}

\begin{abstract}
Methyl esters, derived from natural fats or oils, can be used as alternatives to fatty acids in the production of a number of oleochemicals and their derivatives. Methyl esters are widely used as feedstock for production of other oleochemicals, such as fatty alcohol, alkanolamides, methyl ester sulphonates, isopropyl esters, sucrose polyesters and many more. This Life Cycle Assessment (LCA) study was conducted to identify the environmental impacts from the production of methyl ester using refined, bleached and deodorised palm stearin (RBDPOs) feedstock through transesterification process. The results showed that the most significant impact categories from the production of methyl ester were fossil fuels, respiratory inorganics and climate change. The main contributors to these impacts came from the production of RBDPOs, methanol and steam. These environmental impacts/contributions may be reduced and improved if a green technology is implemented, i.e. by replacing the existing sources of energy that are mainly used for boiler system and energy generation at plant (natural gas and electricity from grid) with renewable resources, e.g. biomass that are abundantly available in the plantation. In addition, bio-methanol may also be considered as an alternative source to replace the methanol from fossil origin in order to reduce the dependency on fossil materials in the future.
\end{abstract}

Keyword: palm-based methyl ester, biodiesel, Life Cycle Impact Assessment, Life Cycle Assessment, environmental impacts.

Date received: 14 April 2017; Sent for revision: 21 April 2017; Received in final form: 9 June 2017; Accepted: 13 July 2017.

\section{INTRODUCTION}

The Malaysian oil palm industry has shown a stable performance with good records in several key performance indicators such as price of palm oil products, crude palm oil production, exports and imports volume as well as revenue. Presently, palm oil is one of the major vegetable oils produced in the world. The total export volume of oil palm products in 2016 (consisting of palm oil, palm kernel oil, palm kernel cake, oleochemicals, biodiesel and finished products) was about 23.29 million tonnes and has

\footnotetext{
* Malaysian Palm Oil Board, 6 Persiaran Institusi, Bandar Baru Bangi, 43000 Kajang,

Selangor, Malaysia.

E-mail: azah@mpob.gov.my
}

earned export revenue of RM 64.59 billion. The total export revenue increased by $7.3 \%$ as compared to 2015 (MPOB, 2017).

The demand for oleochemical products increased due to the expanding of the oleochemical sector and applications. The oleochemical industry in Malaysia currently has the capacity to produce basic oleochemicals such as fatty acids, methyl ester, fatty alcohol, soap noodles and glycerine. In 2016, the major oleochemical products exported were fatty acids (33.4\% of total oleochemical exports), followed by fatty alcohol (20.2\%), methyl ester $(17.3 \%)$, soap noodles $(14.9 \%)$ and glycerine $(14.2 \%)$ (MPOB, 2017).

Methyl ester is known as one of the common basic oleochemicals derived from natural fats or oils that can be used as alternatives to palm-based fatty 
acids in the production of a number of derivatives. There is a demand to substitute palm-based fatty acids with methyl ester as starting materials in the production of several basic oleochemicals and their derivatives. These derivatives include fatty alkanolamides, fatty alcohols, isopropyl esters, and sucrose polyesters. In 2016, Malaysian exported $468027 \mathrm{t}$ of methyl ester, generating revenue about RM 12.720 billion, and this contributed about 17\% of total oleochemical exports from Malaysia. Figure 1 indicates the export volumes of methyl ester from 2008 to 2016.

Several benefits may be realised when methyl esters are used as raw materials, instead of fatty acids, such as the ability to make higher purity finished products, the use of milder conditions during syntheses, and the need for less expensive materials for plant construction. In addition to the applications mentioned, methyl esters are increasingly being used in fractional distillations due to their lower boiling points and are less corrosive than fatty acids (Farris, 1979). Transesterification of oils is the most commonly used process for manufacturing methyl ester, except in cases where methyl ester of single cut fatty acids is needed. Transesterification of triglycerides produces methyl esters and glycerine (Figure 2).
Life Cycle Assessment (LCA) is a good and useful tool to help the industry to promote their products and to give a good perspective to the oil palm industry. Most oleochemical producers have started to establish their own LCA to support their marketing requirement and to provide awareness among their customer. To date, there were several LCA studies conducted on methyl ester, especially as biodiesel/biofuel product. LCA studies on methyl ester as biodiesel product were conducted using several common feedstock, i.e. palm oil, soyabean oil, rapeseed oil, sunflower oil and also tallow. In Malaysia, methyl ester can be used as intermediate product for production of methyl ester sulphonates (MES), methyl ester ethoxylate (MEE) or fatty alcohol. Currently, methyl ester is widely used as a fuel, known as biodiesel, to substitute diesel from petroleum.

Previously, Puah et al. (2010) studied the Life Cycle Impact Assessment (LCIA) on the production and use of palm biodiesel. They investigated the environmental impacts of palm biodiesel produced from refined palm oil (RPO) through transesterification process. This process is similar with the process used in methyl ester production currently being studied, except for the feedstock used. The study concluded that the environmental

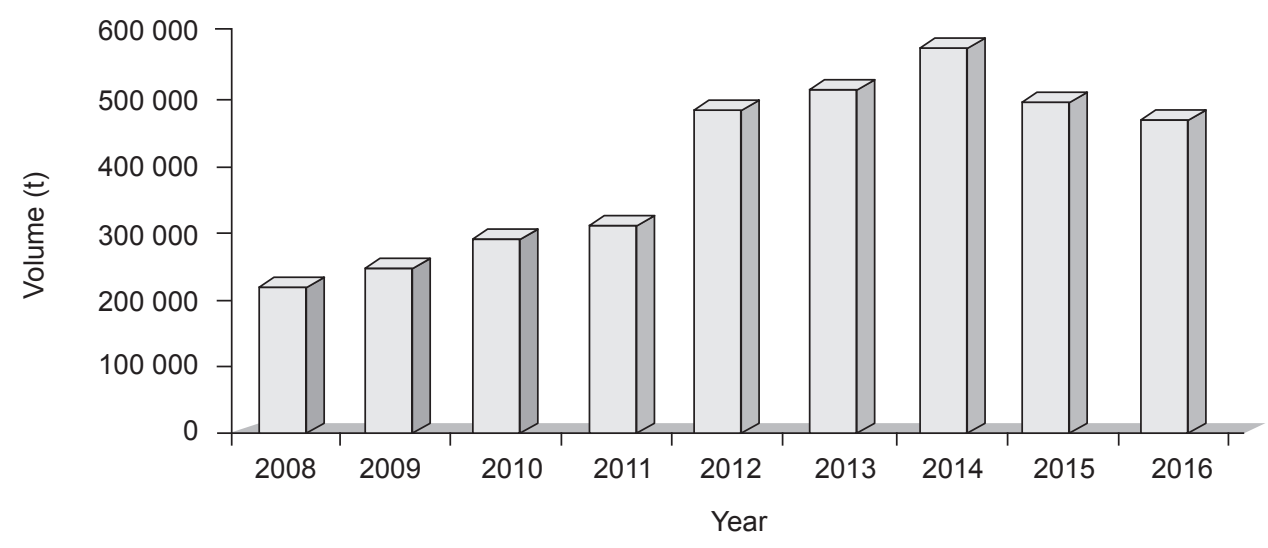

Source: MPOB (2009; 2010; 2011; 2012; 2013; 2014; 2015; 2016; 2017).

Figure 1. Malaysian export of methyl ester, 2008 to 2016.

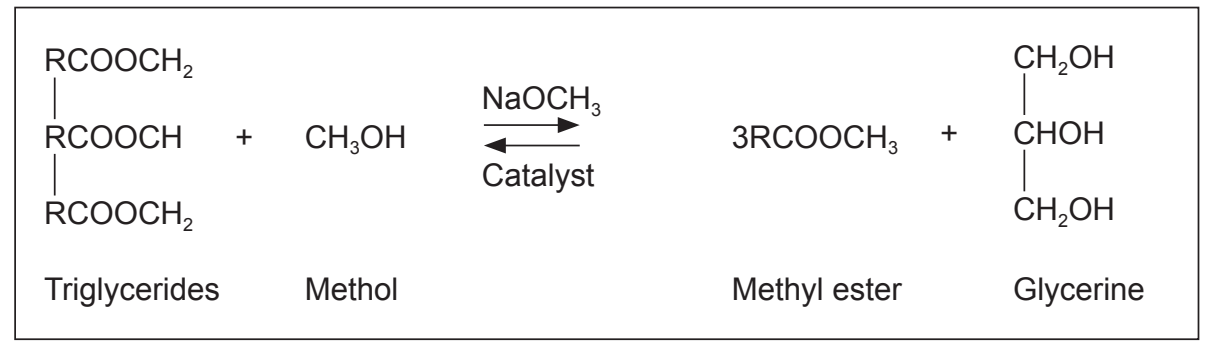

Figure 2. Transesterification between triglycerides and methanol to produce methyl ester and glycerine. 
impacts from the production of palm biodiesel were contributed by the use of methanol. There were also impacts toward respiratory inorganics and acidification/eutrophication categories due to the use of palm biodiesel itself. Even though the system boundary of that study was quite similar to the current study, the functional unit used was different, i.e. based on the production and use of 1 MJ palm biodiesel in diesel engine vehicles.

An LCA study conducted in Argentina on soyabean-based biodiesel (Luis et al., 2008) found that several relevant impact categories were accounted, i.e. the primary non-renewable energy consumption (CED), the global warming potential (GWP), eutrophication potential (EP), acidification potential (AP), terrestrial ecotoxicity (TE), aquatic ecotoxicity (AE), human toxicity (HT) and land use (LU) competition. There were significant influence of the LU change, the nitrogen input value and use of fertiliser, the applied pesticides, the soyabean production method, the use of methanol and the transport system on the environmental impacts. However, in terms of LU competition, Malaysian palm-biodiesel has lower impact compared to Argentina's soyabean-based biodiesel due to none existed impact on the LU impact category.

Hubert et al. (2008) conducted comparative LCA study on two types of fuel, i.e. ethanol from sugar beet and rapeseed methyl ester. The assessment on the environmental impacts showed that rapeseed methyl ester allows a considerable improvement of the environmental performances compared to fossil diesel, while ethanol from sugar beet offers a limited benefits compared to petrol.

Niederl and Narodoslawsky (2004) performed LCA study on biodiesel from tallow and used vegetable oil. They found that methanol, potassium hydroxide and sulphuric acid, used as process chemicals, shared about $22 \%$ of the overall footprint from biodiesel produced using used vegetable oil. Almost the whole footprint of methanol was attributed to the utilisation of fossil carbon. Methanol not only contains carbon of fossil origin, but may also come from renewable carbon-sources. Potassium hydroxide and sulphuric acid contributed minimal impact in the production of biodiesel due to their application as catalyst (insignificant consumption). They also identified potential ways to reduce the ecological footprint, i.e. by using methanol from renewable resources or through the optimisation of transport distances.

Based on the above LCA studies on biodiesel from various feedstocks, there are some points that can be taken into consideration in the current LCA study on methyl ester for oleochemical industry. The current study was performed using established Life Cycle Inventory (LCI) data from methyl ester plant in Malaysia. The objective is to identify the environmental impacts from the production of methyl ester in Malaysia by considering the cradleto-gate system boundary.

\section{METHODOLOGY}

\section{System Boundary and Functional Unit}

Figure 3 shows the system boundary for LCA of the production of methyl ester. The system boundary started from the oil palm seed germination and ended at the production of methyl ester. The use and distribution of methyl ester was excluded in this study. The study was conducted according to ISO 14044 standard (2006). The functional unit used was the production of $1 \mathrm{t}$ of methyl ester.

\section{Data Source and Inventory}

The inventory data were collected directly from one commercial methyl ester producer in Malaysia through actual on-site measurement and quantification, which include all the feedstock, chemicals, energy, water, emissions and wastes that had been used and produced during the production of methyl ester. Sources of data for this study started from the production of oil palm germinated seed until methyl ester production as listed in Table 1. The data validation procedures were carried out through communication and discussions via e-mail and telephone, on-site visits and also interviews with the methyl ester producer in order to verify the reliability of the data collection.

\section{Life Cycle Impact Assessment (LCIA)}

Impact assessment analyses were conducted using SimaPro software version 8.0.2 and Ecoindicator 99 as methodology for the study. This assessment used the midpoint approach where the results are more meaningful from a scientific perspective since this approach is problemoriented approach that translates the impacts into environmental themes such as climate change, fossil fuels, land use, etc. This methodology is aimed at identifying energy and materials used and emissions to the environment. The LCI obtained through the detailed inventory were then calculated to determine the environmental impact and the results interpreted and evaluated to identify possible improvement opportunities. The impacts were assessed through single score and weighting results. Single score shows the contribution of each input parameter to each impact category. While, weighting is the process of converting indicator results of different impact categories by using numerical factors based on value-choices. It may include aggregation of the weighted indicator results. Different value- 


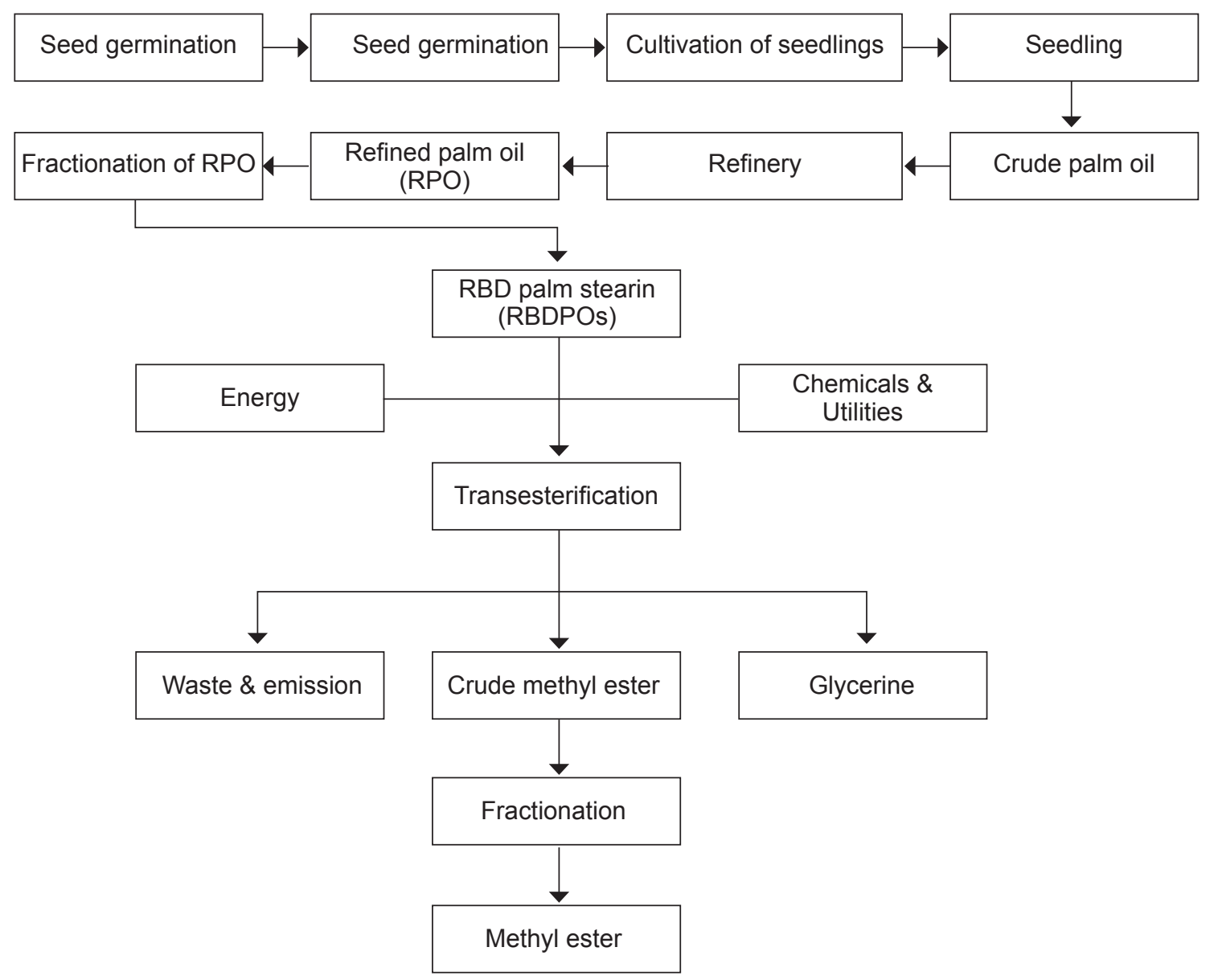

Note: RBD - refined, bleached and deodorised.

Figure 3. System boundary for the production of methyl ester via transesterification process.

TABLE 1. SOURCES OF INVENTORY DATA FOR LIFE CYCLE ASSESSMENT (LCA) OF METHYL ESTER

\begin{tabular}{lc}
\hline Life cycle stage & Data source \\
\hline Oil palm nursery & Halimah et al. (2010) \\
Oil palm plantation & Zulkifli et al. (2010) \\
Palm oil mill & Vijaya et al. (2010) \\
Fractionation of palm product & Yew Ai et al. (2010) \\
Methyl ester & Commercial plant, Malaysia \\
\hline
\end{tabular}

choices are given to impact categories to generate a single score. Weighting steps are based on value-choices and are not scientifically based (ISO 14044:2006). Two scenarios for methyl ester production were studied as follows:

i) Scenario 1: production of methyl ester; transesterification process; uses electricity from grid; continued land use; with biogas capture.

ii) Scenario 2: production of methyl ester; transesterification process; uses biomass to replace electricity from grid; continued LU; with biogas capture.
Continued LU is refers to the cultivation of oil palm at the expense of oil palm, i.e. replanting, so there is no LU change involved. In Malaysia, the optimal replanting age of palm lies between 25 and 26 years (Azman and Mohd Noor, 2002). While, biogas capture is a facility installed at the palm oil mill to capture the biogas produced from palm oil mill effluent (POME).

\section{Sensitivity Analysis}

The sensitivity analysis in the LCA study is carried out in order to investigate changes in calculation of the total result of the LCA by assigning different values of the key figures in the study, while all other are unchanged. According to the ISO 14044:2006 (E), sensitivity analysis is a procedure to determine how changes in data affect the results of the LCIA (ISO, 2006). The sensitivity analysis was carried out on the production of methyl ester using this scenario, i.e. the production of methyl ester though transesterification process, with continued LU, uses electricity from grid and without biogas capture facility at the palm oil mill. 


\section{RESULTS AND DISCUSSION}

\section{Life Cycle Inventory (LCI)}

LCI data are inventory data that have been calculated to quantify the environmental inputs and outputs of the functional unit within the system boundary. The inventory data for the production of methyl ester were obtained from a commercial methyl ester plant in Malaysia through questionnaires. Validation and verification processes were carried out and reviewed with the technical team of the methyl ester plant. The environmental inputs to produce $1 \mathrm{t}$ of methyl ester include refined, bleached and deodorised (RBD) palm stearin (POs), sodium hydroxide, hydrochloric acid, phosphoric acid, methanol, catalyst, water, steam, electricity as energy source, natural gas and nitrogen for blanketing purposes (Table 2).

The energy used as power source to start the methyl ester plant production was non-renewable energy. Electricity was generated at the power stations as national grid source, where fossil fuels were consumed and wastes were generated. The electricity process flow was identified from mining and extraction of fossil fuel, processing, production and distribution to the grid at the points of use. The electricity data employed in this study was taken from the Malaysian electricity profile.

The other input was water, used as the source of cooling water, boiler feed water, steam as well as water for plant process. This water is normally classified as tap water, decarbonised water or deionised water. Another use of water in the plant was for cleaning and washing. In methyl ester production, cooling water was used for heat exchanger while nitrogen was used for blanketing and flushing the plant line. Other than that, sodium methoxide was used as catalyst in the process. Meanwhile, data on by-products from the production, i.e. glycerine and intermediate methyl ester products, were self-generated as no data were

TABLE 2. LIST OF INPUT AND OUTPUT FOR METHYL ESTER PRODUCTION

\begin{tabular}{cc}
\hline Input & Output \\
\hline RBDPOs & Methyl ester \\
Sodium hydroxide & Glycerine \\
Hydrochloric acid & Intermediate products \\
Phosphoric acid & Wastewater \\
Methanol & Solid waste \\
Catalyst & Emission \\
Water & \\
Steam & \\
Electricity & \\
Natural gas & \\
Nitrogen &
\end{tabular}

Note: RBDPOs - refined, bleached and deodorised palm stearin. found in the database. The emission reported was identified as methanol gases.

The raw glycerine obtained as a by-product from methyl ester production was $80 \%$ pure and it will be sold to methyl ester plant in order to produce higher grade glycerine for industrial application. Glycerine of different purity has different application in the oleochemical industry. In view of this, weight allocation has been conducted to allocate part of inputs and outputs to glycerine. The allocation between methyl ester and glycerine was set at $89 \%$ and $11 \%$, respectively.

\section{Life Cycle Impact Assessment (LCIA)}

Scenario 1. Figures 4 and 5 show the single score and weighting results, respectively, for Scenario 1, where continued LU was practised in oil palm plantation and biogas capture facility was used in the palm oil mills. The continued LU and biogas capture scenario was the best scenario for the upstream and midstream activities of the oil palm industry (Noorazah et al., 2015). This study showed that RBDPOs was one of the main impact contributors during the production of methyl ester, followed by methanol and steam.

It is important to point out that almost the whole footprint of methanol was an attribute to the utilisation of fossil carbon (Niederl and Narodoslawsky, 2004). With the input of methanol in methyl ester production, the carbon of methyl ester came not only from renewable carbon-source, but also contained carbon of fossil origin. Methanol contributed $15 \%$ of the overall impact contribution on fossil fuels impact category due to the depletion of fossil resources, i.e. natural gas, during methanol production. Natural gas was also used to heat up thermal oil in the boiler to generate the steam. Meanwhile, the impact contributed by electricity and catalyst were minimal as shown in Figure 4. Overall, all the impacts led to a higher contribution on fossil fuels due to the non-renewable resources used in the production especially during the upstream activities and methanol production (Figure 5).

Impact on respiratory inorganics was associated with emissions to the atmosphere, i.e. from the boiler that generates steam. The impact on respiratory inorganics was also contributed by activities that were associated with the plantation, such as production and application of fertiliser, fuel used for machinery and transport of materials into and out of the plantation. Meanwhile, the impact on climate change was contributed from the biogas generated by palm oil mill effluent, even though the biogas capture facility is used at the mill as reported by Yew Ai et al. (2010). For Scenario 1 study, the degrees of magnitude of impact significance are as follows: fossil fuels > respiratory inorganics $>$ climate change. 


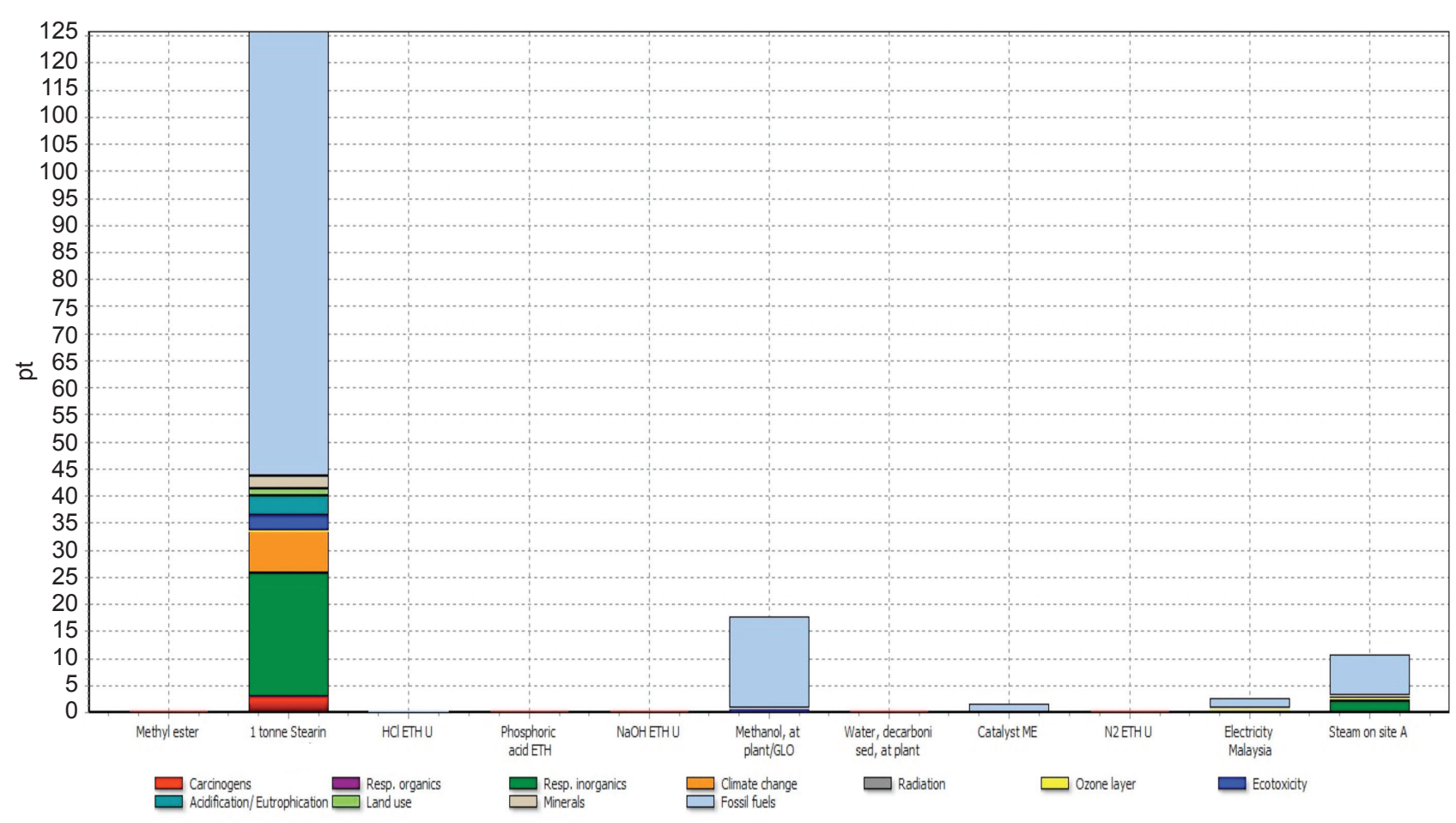

Figure 4. Single score for Life Cycle Impact Assessment (LCIA) of 1 t of methyl ester - Scenario 1.

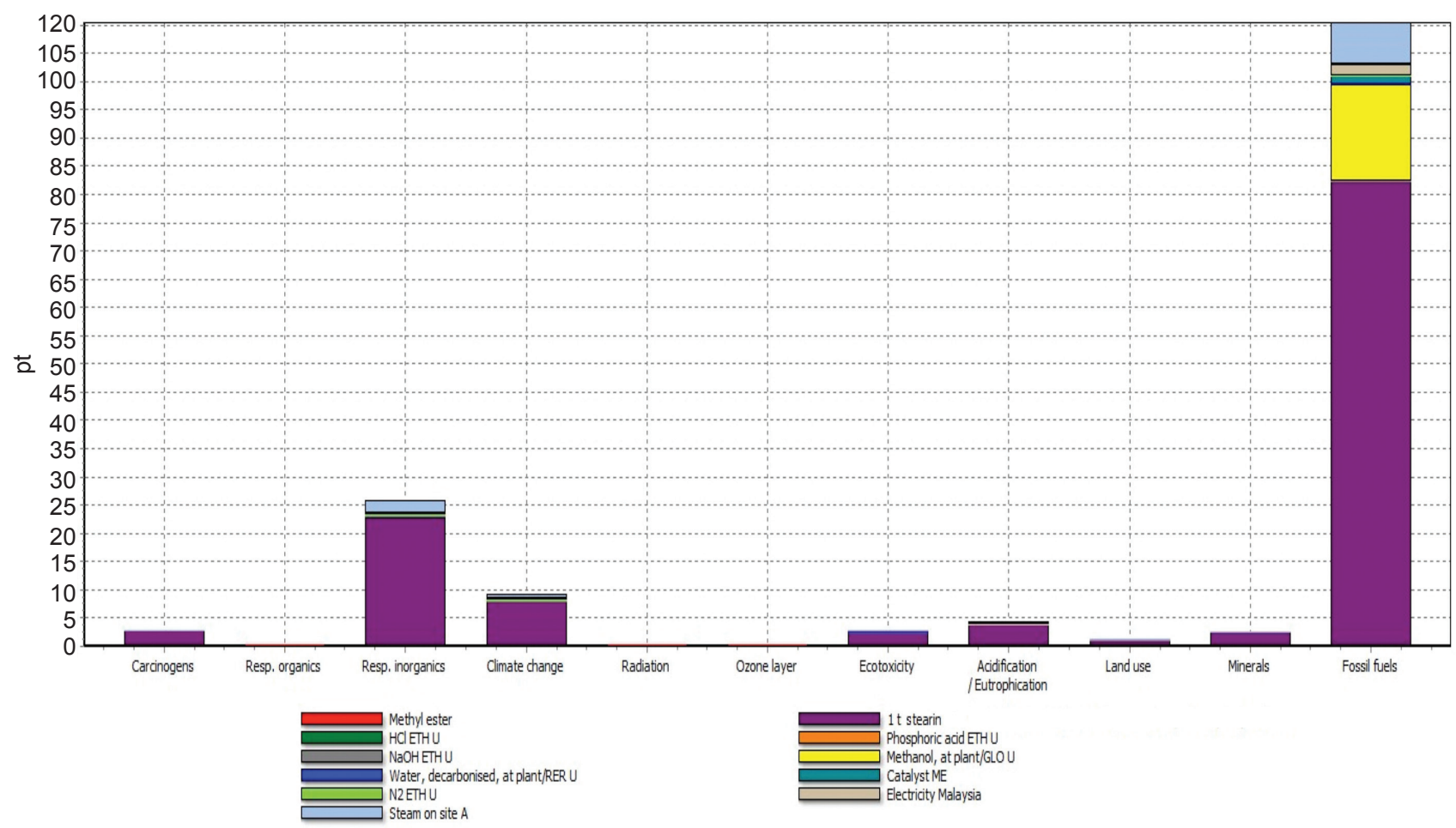

Figure 5. Weighting for Life Cycle Impact Assessment (LCIA) of 1 t of methyl ester - Scenario 1.

Scenario 2. This scenario was carried out in order to gauge the impacts when possible improvement is made to the system being studied. The electricity generated from national grid was substituted with oil palm biomass, i.e. a combination of shell and mesocarp fibre. These oil palm biomass are actually wastes from fresh fruit bunches (FFB) and then recycled as boiler fuel (Noorazah et al., 2015). It was well established that most of palm oil mills in Malaysia are using this valuable by-product as 
fuel for boiler to produce heat for conversion of water into steam. The energy was produced from renewable resources and it can help to reduce impact on climate change category even in smaller amount. The single score and weighting results for this scenario are shown in Figures 6 and 7, respectively. In this scenario, the impact on climate change category was reduced about $2 \%$ compared to Scenario 1. Therefore, the use of palm biomass could be considered as an efficient approach to reduce the dependency on fossil materials in energy production.

\section{Sensitivity Analysis}

The sensitivity analysis is mainly carried out in order to determine the impact of changing inputs in the upstream activities of methyl ester production. It is well-known that in Malaysia all plantations are from continued LU and no more logged over forest being converted to oil palm plantation. As reported by Loh et al. (2016), almost $20 \%$ of the palm oil mills in Malaysia have implemented biogas capture facility/system as of November 2016. Thus, the sensitivity analysis was carried out by considering if the feedstock used in the methyl ester production, i.e. RBDPOs, was obtained from palm oil mill without biogas capture facility. The sensitivity analysis scenario was compared with Scenario 1 which is the base case scenario for methyl ester production as conducted previously. The single score and weighting results are shown in Figures 8 and 9 , respectively.
It was observed that the impact from the feedstock in this sensitivity analysis was $16 \%$ higher compared to Scenario 1. In addition, the impact on fossil fuels category increased about $9 \%$ as compared to Scenario 1 . As expected, the climate change impact value also increased due to the biogas emissions emitted during the production of feedstock, i.e. $56 \%$ higher compared to Scenario 1. The percent of difference for selected impact categories from both scenarios are shown in Table 3.

From the sensitivity analysis, it can be concluded that the biogas emissions from the palm oil mill can increase the intensity of the impact on fossil fuels and climate change impact categories. The use of biogas capture facility, as in Scenario 1, also help to reduce the impact in several impact categories, i.e. climate change, ecotoxicity,

\section{TABLE 3. PERCENT OF DIFFERENCE FOR SELECTED IMPACT CATEGORIES BETWEEN SCENARIO 1 AND SENSITIVITY ANALYSIS SCENARIO}

\begin{tabular}{lrcr}
\hline $\begin{array}{l}\text { Impact } \\
\text { category }\end{array}$ & $\begin{array}{c}\text { Scenario 1 } \\
\text { (in Pt) }\end{array}$ & $\begin{array}{c}\text { Sensitivity } \\
\text { analysis } \\
\text { (in Pt) }\end{array}$ & \% Difference \\
\hline Climate change & 9.098 & 20.802 & 56.3 \\
Ecotoxicity & 2.753 & 3.419 & 19.5 \\
Acidification/ & & & \\
$\quad$ eutrophication & 4.272 & 5.633 & 24.2 \\
Land use & 1.207 & 1.457 & 17.2 \\
Minerals & 2.481 & 2.510 & 1.2 \\
Fossil fuels & 110.411 & 120.904 & 8.7 \\
\hline
\end{tabular}

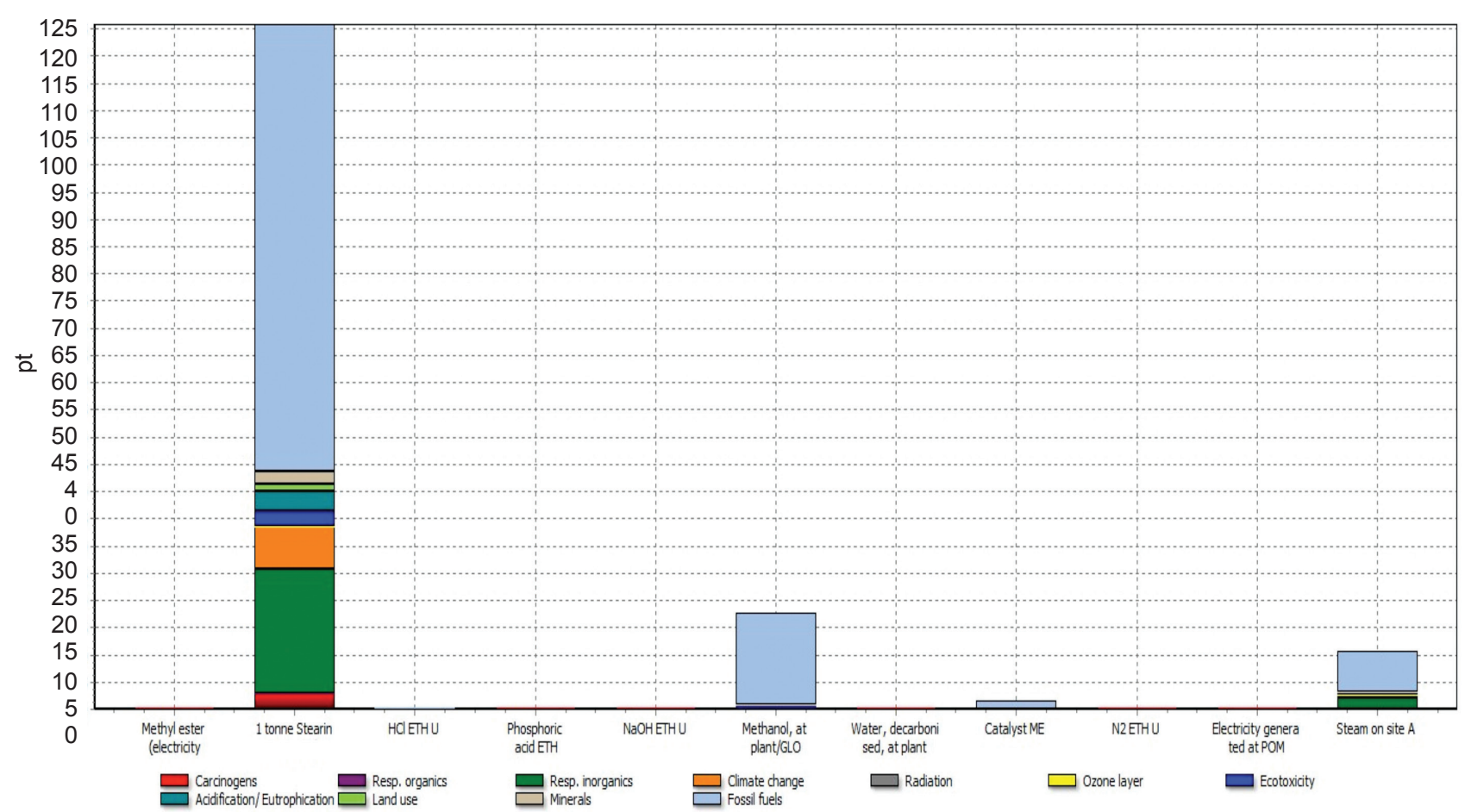

Figure 6. Single score for Life Cycle Impact Assessment (LCIA) of 1 t of methyl ester - Scenario 2. 


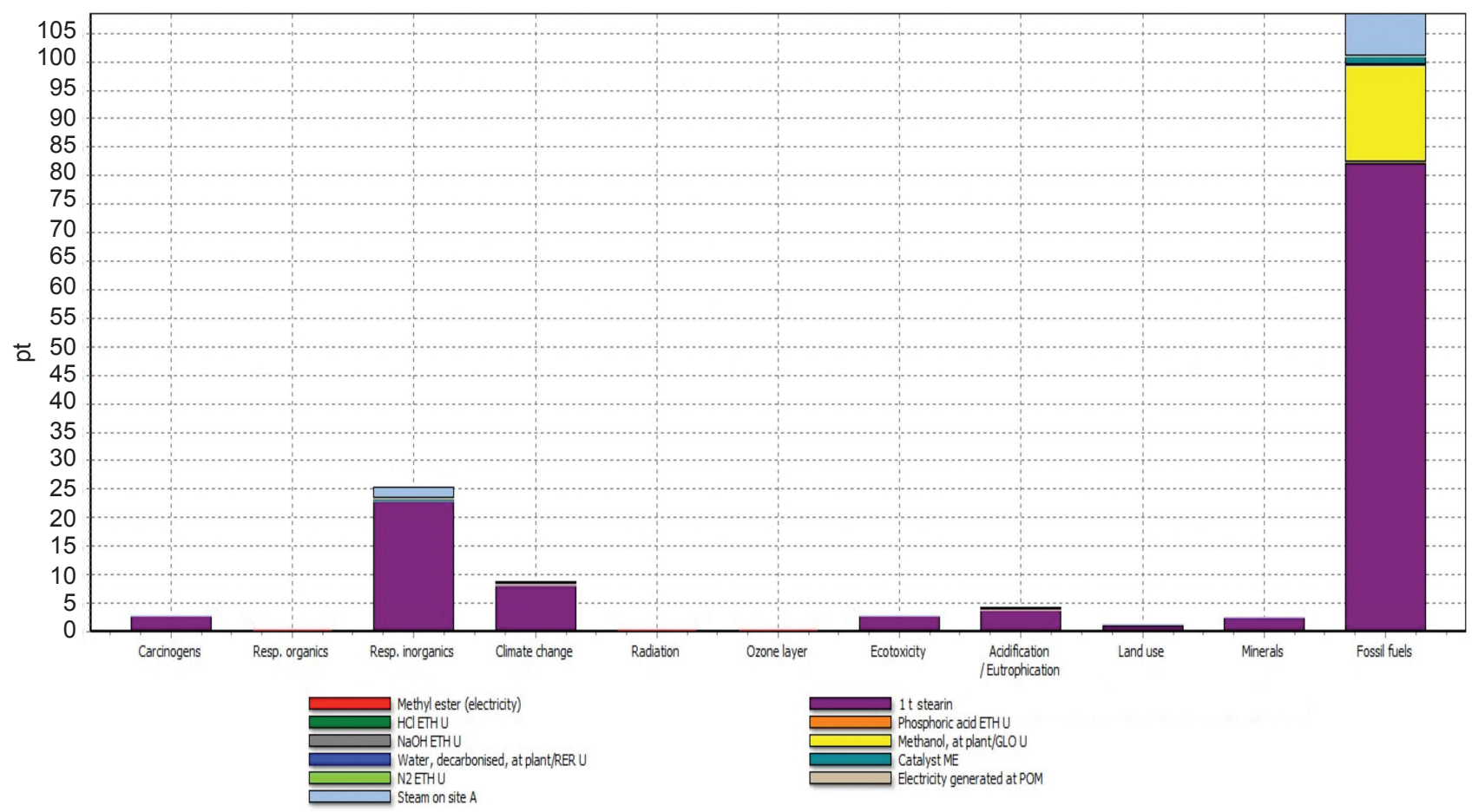

Figure 7. Weighting for Life Cycle Impact Assessment (LCIA) of 1 t of methyl ester - Scenario 2.

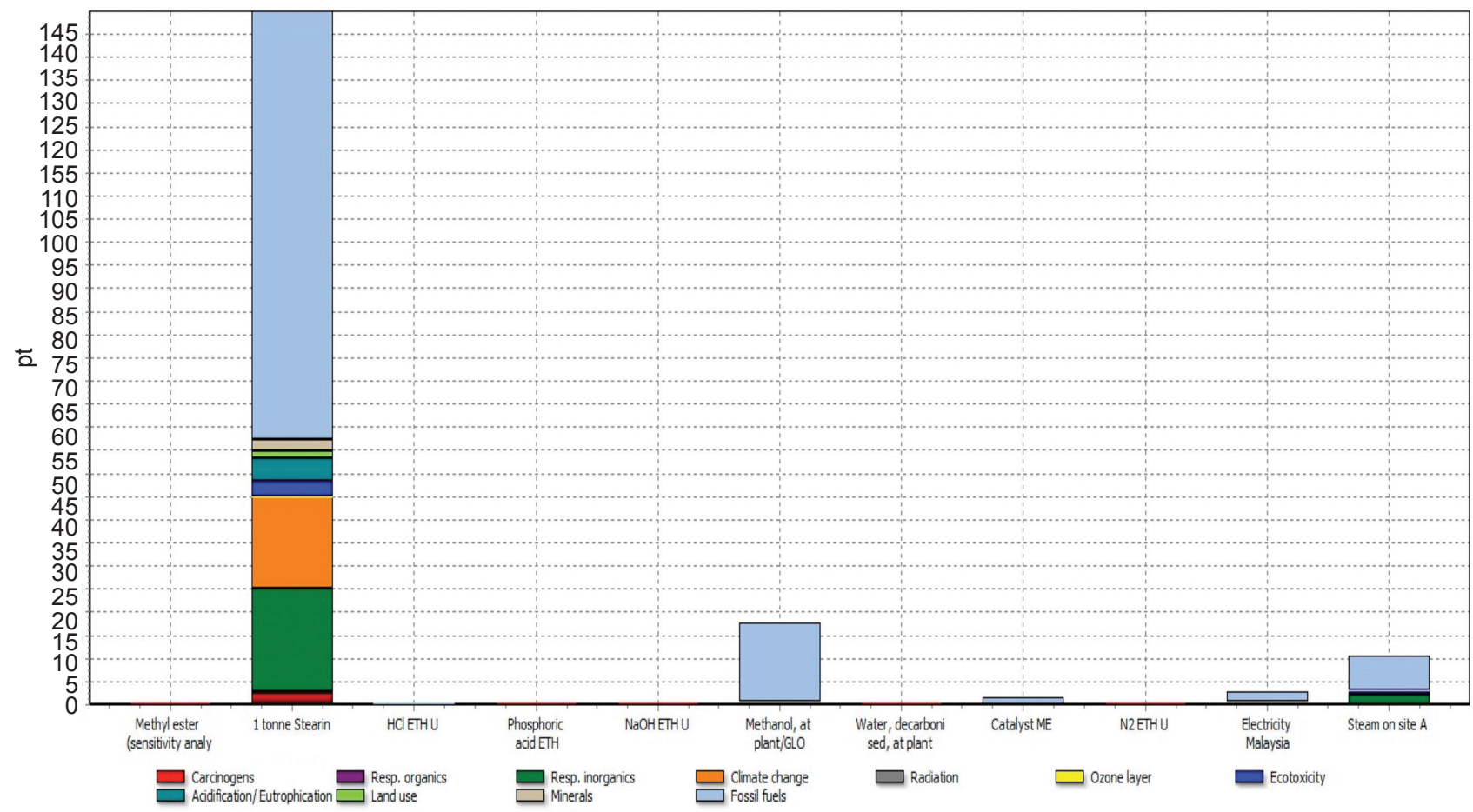

Figure 8. Single score for Life Cycle Impact Assessment (LCIA) of 1 t of methyl ester - sensitivity analysis.

acidification, LU and fossil fuels as listed in Table 3. Even though the biogas capture facility is mostly associated to the palm oil mill, but the contribution impact using this facility should also be considered and be taken as a part of the impact for the whole methyl ester production due to the cradle-to-gate system boundary.

\section{CONCLUSIONS AND RECOMMENDATIONS}

The findings of this study were analysed based on Eco-indicator 99 methodology with cradle-togate system boundary using RBDPOs feedstock in the production of methyl ester through transesterification process. Based on the analyses, 


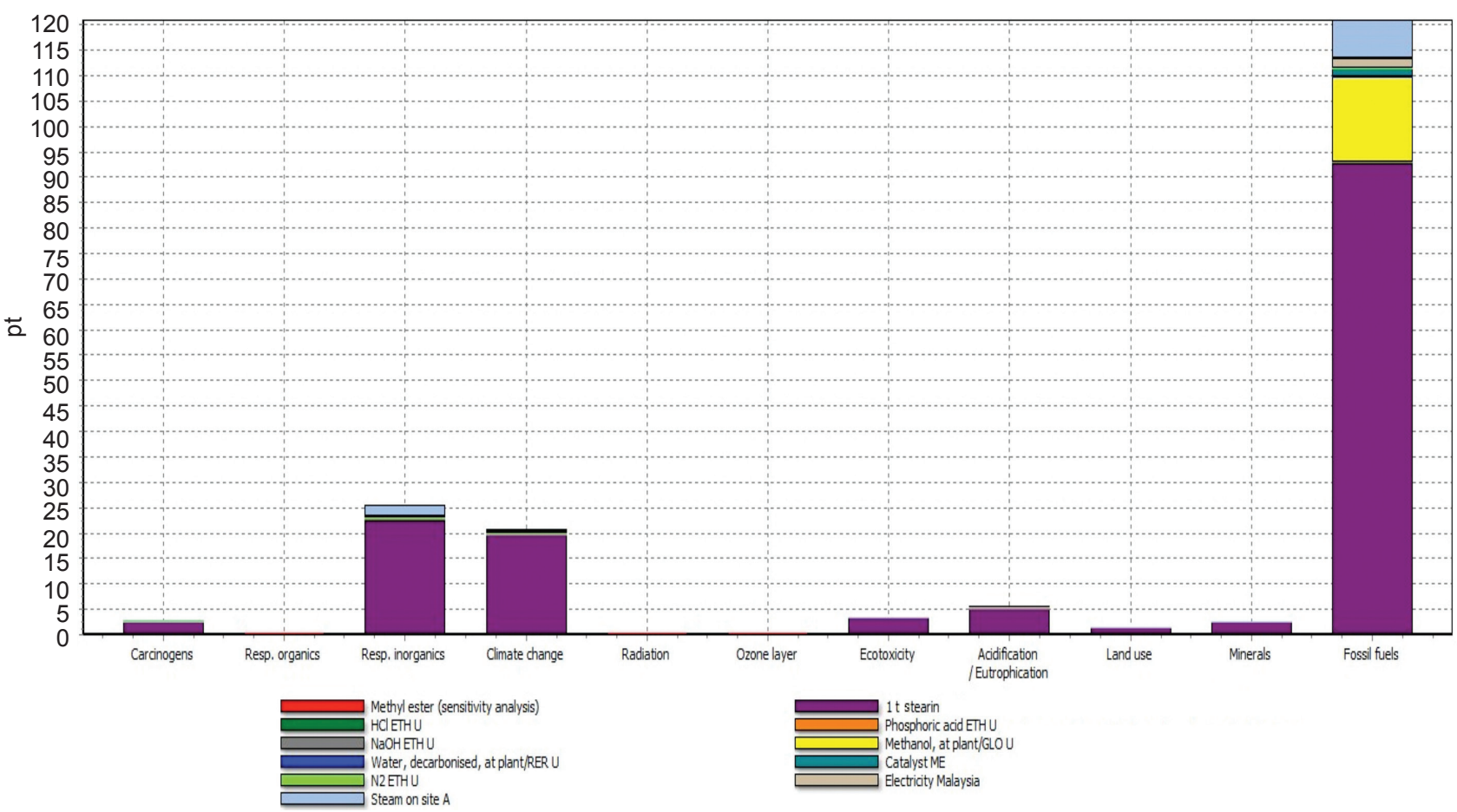

Figure 9. Weighting for Life Cycle Impact Assessment (LCIA) of 1 t of methyl ester - sensitivity analysis.

the main significant impact categories were fossil fuels, followed by respiratory inorganics and minimalimpact from climate change category. These impacts were directly contributed by RBDPOs, methanol and some of the utilities used, i.e. natural gas, steam and electricity. The best scenario for the production of RBDPOs as feedstock was from palm oil mill with a biogas capture facility which is described as in Scenario 1. The environmental impacts / contributions may be further reduced and improved if a green technology is implemented, i.e. by replacing the existing sources of energy mainly used for boiler system and energy generation at plant (natural gas and electricity from grid) with renewable resources, such as biomass, that are abundantly available in the plantation. In addition, bio-methanol may also be considered as an alternative source to replace the methanol from fossil origin in order to reduce the dependency on fossil materials in its production, i.e. natural gas and coal in the future. The use of biogas capture facility to trap biogas emissions at palm oil mill can further help to reduce several impacts generated during the methyl ester production as highlighted in this study.

\section{ACKNOWLEDGEMENT}

The authors would like to thank the DirectorGeneral of MPOB for permission to publish this article. The authors would also like to express their gratitude to the methyl ester producer involved in the LCA study of methyl ester production for their data and contribution.

\section{REFERENCES}

AZMAN, I and MOHD NOOR, M (2002). The optimal age of oil palm replanting. Oil Palm Industry Economic Journal Vol. 2 (1): 11-18.

FARRIS, R D (1979). Methyl ester in the fatty acids industry. J. Amer. Oil Chem. Soc. 56 (11): 770A-773A. http: / / link.springer.com/article/10.1007 / BF02667441

HALIMAH, M; ZULKIFLI, H; VIJAYA, S; YEW, A T; PUAH, C W and CHOO, Y M (2010). Life cycle assessment of oil palm seedling production (part 1). J. Oil Palm Res. Vol. 22: 878-886. http://jopr.mpob. gov.my / life-cycle-assessment-of-oil-palm-seedlingproduction-part-1/

HUBERT, H; STEPHANE, L and ROBERT, R (2008). Comparative life cycle assessment of two fuels. Ethanol from sugar beet and rapeseed methyl ester. The International J. LCA, 13(3):184-190. https:// www.researchgate.net/ publication / 225989105_ Comparative_life_cycle_assessment_of_two_ biofuels_Ethanol_from_sugar_beet_and_rapeseed_ methyl_ester 
INTERNATIONAL ORGANISATION FOR STANDARDIZATION (2006). ISO 14044: Environmental Management - Life Cycle Assessment - Requirements and Guidelines. 2006 Edition.

LOH, S K; NASRIN, A B; MOHAMAD AZRI, S; NURUL ADELA, B; MUZZAMMIL, N; DARYL, J T; STASHA, E R A and LIM, W S (2016). Update on biogas capture and utilization. Paper presented at the POMREQ 2016. 29-30 November 2016, Kuala Lumpur, Malaysia.

LUIS, P; ARNAUD, D and EDGARD, G (2008). Life cycle assessment of soyabean-based biodiesel in Argentina for export. The International J. LCA, 14: 144159. https://infoscience.epfl.ch/record/125175/ files / Life $\% 20$ cycle $\% 20$ assessment $\% 20$ of $\% 20$ s oy be a n - b a sed $\% 20$ bi odiese $1 \% 20$ in $\% 20$ Argentina $\% 20$ for $\% 20$ export.pdf

MPOB (2008). Malaysian Palm Oil Statistic 2008. MPOB, Bangi, Malaysia.

MPOB (2009). Malaysian Palm Oil Statistic 2009. MPOB, Bangi, Malaysia.

MPOB (2010). Malaysian Palm Oil Statistic 2010. MPOB, Bangi, Malaysia.

MPOB (2011). Malaysian Palm Oil Statistic 2011. MPOB, Bangi, Malaysia.

MPOB (2012). Malaysian Palm Oil Statistic 2012. MPOB, Bangi, Malaysia.

MPOB (2013). Malaysian Palm Oil Statistic 2013. MPOB, Bangi, Malaysia.

MPOB (2014). Malaysian Palm Oil Statistic 2014. MPOB, Bangi, Malaysia.

MPOB (2015). Malaysian Palm Oil Statistic 2015. MPOB, Bangi, Malaysia.

MPOB (2016). Malaysian Palm Oil Statistic 2016. MPOB, Bangi, Malaysia.

NIERDEL, A and NARODOSLAWSKY, M (2004). Report: Life Cycle Assessment - Study of Biodiesel from
Tallow and Used Vegetable Oil. Institute for Resource Efficient and Sustainable Systems. http://www. cti2000.it / Bionett / BioD-2004-101\% 20LCA \% 20 of $\% 20$ biodiese $\% 20$ from $\% 20$ tallow $\% 20 \% 26 \% 20$ used $\% 20$ oils.pdf

NOORAZAH, Z; SUMIANI, Y; VIJAYA, S; ZULINA, A M; ZAILAN, A B; RAZMAH, G and HAZIMAH, A $H$ (2015). Evaluation of environmental impacts and GHG of palm polyol production using Life Cycle Assessment approach. J. Oil Palm Res. Vol. 27(2): 144-155. https://www.researchgate. net / publication / 279869051_Evaluation_of_ environmental_impacts_and_GHG_of_palm_ polyol_production_using_life_cycle_assessment_ approach

PUAH, C W; CHOO, Y M and MA, A N (2010). Life cycle assessment for the production and use of palm biodiesel (part 5). J. Oil Palm Res. Vol. 22: 927-933. http: / / www.palmoilworld.org/PDFs / Environment/12-joprv22dec10-Puah_LCA5.pdf

VIJAYA, S; CHOO, Y M; HALIMAH, M; ZULKIFLI, H; YEW, A T and PUAH, C W (2010). Life cycle assessment of the production of crude palm oil (part 3). J. Oil Palm Res. Vol. 22: 895-903. http:/ / jopr.mpob. gov.my / life-cycle-assessment-of-the-production-ofcrude-palm-oil-part-3/

YEW AI, T; HALIMAH, M; ZULKIFLI, H; VIJAYA, S; PUAH, C W; CHONG, C L; MA, A N and CHOO, Y M (2010). Life cycle assessment of refined palm oil production and fractionation (part 4). J. Oil Palm Res. Vol. 22: 913-926. http: / / jopr.mpob.gov.my / lifecycle-assessment-of-refined-palm-oil-productionand-fractionation-part-4/

ZULKIFLI, H; HALIMAH, M; CHAN, K W; CHOO, Y M and MOHD BASRI, W (2010). Life cycle assessment for oil palm fresh fruit bunch production from continued land use for oil palm planted on mineral soil (part 2). J. Oil Palm Res. Vol. 22: 887-894. http: / / jopr.mpob.gov.my / life-cycle-assessmentfor-oil-palm-fresh-fruit-bunch-production-fromcontinued-land-use-for-oil-palm-planted-onmineral-soil-part-2 / 